\title{
Risperidone Potentiates the Sympathetic and Hyperthermic Reactions Induced by Orexin A in the Rat
}

\author{
M. MONDA, AN. VIGGIANO, AL. VIGGIANO, E. VIGGIANO, V. DE LUCA \\ Department of Experimental Medicine, Section of Human Physiology, Second University of Naples, \\ Naples, Italy
}

Received February 7, 2005

Accepted March 23, 2005

On-line available April 26, 2005

\begin{abstract}
Summary
This experiment tested the effect of risperidone on the sympathetic and thermogenic effects induced by orexin A. The firing rates of sympathetic nerves to interscapular brown adipose tissue (IBAT), along with IBAT and colon temperatures and heart rate were monitored in urethane-anesthetized male Sprague-Dawley rats before an injection of orexin A (1.5 nmol) into the lateral cerebral ventricle and over a period of 2 hours after the injection. The same variables were monitored in rats with an intraperitoneal administration of risperidone $(50 \mathrm{mg} / \mathrm{kg} \mathrm{bw})$, injected $30 \mathrm{~min}$ before the orexin administration. The results show that orexin A increases the sympathetic firing rate, IBAT, colonic temperatures and heart rate. This increase is enhanced by the injection of risperidone. These findings suggest that risperidone elevates the responses due to orexin, probably through an involvement of serotoninergic and dopaminergic pathways, which are affected by risperidone. Furthermore, we suggested the name "hyperthermine A" as additional denomination of "orexin A" by considering the strong influence of this neuropeptide on body temperature.
\end{abstract}

\section{Key words}

Body temperature $\bullet$ Orexin A $\bullet$ Rat $\bullet$ Risperidone $\bullet$ Sympathetic activity

\section{Introduction}

Orexin A, so-called for its influence on eating behavior (Lubkin and Stricker-Krongrad 1998, Sweet et al. 1999), is a hypothalamic neuropeptide that induces a potent hyperthermia when injected into a lateral cerebral ventricle in the rat (Monda et al. 2001). This increase in body temperature is due to activation of the sympathetic nervous system, as demonstrated by recording from sympathetic fibers innervating the interscapular brown adipose tissue (IBAT). The hyperthermia induced by an intracerebroventricular (icv) injection is independent of the food intake, because the elevation of body temperature is also present in anesthetized rats or in animals without access to food (Monda et al. 2003a, 2004a). For these reasons, an additional term hyperthermine $\mathrm{A}$ has been proposed for this peptide to emphasize its main role in thermoregulation (Monda et al. 2003a, 2004a).

The sympathetic and hyperthermic reactions due to orexin A are modified by some antipsychotic drugs. Indeed, administration of haloperidol reduces these reactions (Monda et al. 2003b), while clozapine completely blocks sympathetic and thermogenic reactions induced by orexin A in the rat (Monda et al. 2004b). 
Risperidone, an atypical antipsychotic drug (Masan 2004), can modify body temperature. There is evidence showing that both hypothermia (Razaq and Samma 2004) and hyperthermia (Ananth et al. 2004, Halloran and Bernard 2004) are also affected by risperidone. This suggests an influence of this drug on thermoregulation.

The aim of the present experiment was to test the influence of risperidone on sympathetic and hyperthermic reactions due to an intracerebroventricular (icv) injection of orexin A.

\section{Methods}

Animals

Male Sprague-Dawley rats $(\mathrm{n}=24$, divided into 4 groups of 6 animals each), 3 months old and weighing 260-310 g were used in the experiments. The rats were housed in pairs at controlled temperature $\left(22 \pm 1{ }^{\circ} \mathrm{C}\right)$ and humidity $(70 \%)$ with a $12: 12 \mathrm{~h}$ light-dark cycle with light from 07:00 to 19:00 $\mathrm{h}$. The experiments were in accordance with the European Communities Council Directive of November 24, 1986 (86/609/EEC).

\section{Apparatus}

A pair of silver wire electrodes recorded the firing rate of nerves to IBAT. The electrical pulses were amplified by a condenser-coupled amplifier and were filtered by band-pass filters (NeuroLog System, Digitimer). The raw pulses were displayed on an oscilloscope (Tektronix) and sent to a window discriminator. Square waves from the discriminator were processed by an analog-digital converter (DAS system, Keithley) and stored on a computer (Personal Computer AT, IBM) every $5 \mathrm{~s}$. A ratemeter with a reset time of $5 \mathrm{~s}$ was also used to observe the time course of the nerve activity recorded by a pen recorder (Dynograph, Beckman). Because the signal-to-noise ratio depended on the number of nerve filaments and the condition of contact between nerve and electrodes, the basal burst rates were different for each rat. The threshold level of the event detector was fixed during the experiment at $50 \%$ of the peaks of the largest pulses and above background noise.

Thermocouples (Ellab) were used to monitor colonic and IBAT temperatures $\left(\mathrm{T}_{\mathrm{C}}\right.$ and $\left.\mathrm{T}_{\mathrm{IBAT}}\right)$ and the values were stored on a chart recorder.

Two electrodes applied to the forelegs monitored the heart rate (beats/min). Electrical signals were addressed to a polygraph (Dynograph, Beckman) to register the electrocardiographic activity on a card and computer disk.

\section{Drugs and doses}

Orexin A and risperidone were purchased from Peninsula, England and Lilly, Italy, respectively. We used a dose of $1.5 \mathrm{nmol}$ of orexin $\mathrm{A}$, which was selected on the basis of a preliminary experiment with doses of $0.15,1.5$ and $15 \mathrm{nmol}$ in three groups of 2 rats each. This test showed a dose-effect curve on colonic temperature. The temperature modifications were: a) from $37.09 \pm 0.18$ to $37.69 \pm 0.16^{\circ} \mathrm{C}$ with dose of $0.15 \mathrm{nmol}$; b) from $37.15 \pm 0.10$ to $38.42 \pm 0.20{ }^{\circ} \mathrm{C}$ with $1.5 \mathrm{nmol}$; c) from $37.18 \pm 0.12$ to $38.72 \pm 0.23{ }^{\circ} \mathrm{C}$ with $15 \mathrm{nmol}$. Since the low number of animals did not permit a statistical analysis, these experiments were merely preliminary to determine the appropriate dose. We chose the submaximal dose of $1.5 \mathrm{nmol}$ (dissolved in $5 \mu \mathrm{l}$ of $0.9 \% \mathrm{NaCl}$ sterile solution) for icv injections.

A dose of $50 \mathrm{mg} / \mathrm{kg}$ b.w. of risperidone (dissolved in $2 \mathrm{ml}$ of $0.9 \% \mathrm{NaCl}$ sterile solution) was used for intraperitoneal administrations. This dose was chosen after a preliminary experiment on 3 rats. Pretreatment with $5 \mathrm{mg} / \mathrm{kg}$ bw of risperidone induced temperature elevation of $0.31 \pm 0.12{ }^{\circ} \mathrm{C}$ in the orexin-induced hyperthermia. Doses of 50 or $100 \mathrm{mg} / \mathrm{kg}$ b.w. of risperidone induced temperature elevations of $3.95 \pm 0.48$ or $4.27 \pm 0.52{ }^{\circ} \mathrm{C}$, respectively.

\section{Surgery}

All animals were anesthetized with ip pentobarbital $(50 \mathrm{mg} / \mathrm{kg}$ b.w.) and a 20 -gauge stainless guide cannula was positioned stereotaxically (Pellegrino et al. 1979) above a lateral cerebral ventricle at the following coordinates: $1.7 \mathrm{~mm}$ lateral to the midline, $0.4 \mathrm{~mm}$ posterior to the bregma, $3.0 \mathrm{~mm}$ from the cranial theca. The rats were given 7-10 days to recover from surgery judged by recovery of preoperative body weight.

\section{Procedure}

After recovery, the animals were anesthetized with ethyl-urethane (1.2 g/kg b.w. ip) and mounted in a stereotaxic instrument (Stoelting). The level of anesthesia was kept constant and evaluated by skeletal muscle relaxation, eye and palpebral responses to stimuli. Nerve activity was recorded by small nerve bundles dissected from the intercostal nerves supplying the right side of IBAT. Nerve filaments were isolated from the central cut end of these nerve bundles under a dissecting microscope; the efferent activity was recorded with a pair of silver wire electrodes. The nerve filaments were covered with a mixture of vaseline and liquid petroleum at $37{ }^{\circ} \mathrm{C}$ to avoid dehydration. Furthermore, the heart rate, $\mathrm{T}_{\mathrm{C}}$ and $\mathrm{T}_{\mathrm{IBAT}}$ were 
monitored at the same time as the nerve activity was recorded. $T_{C}$ was measured by inserting the thermocouple into the colon $4 \mathrm{~cm}$ from the anus, while $\mathrm{T}_{\mathrm{IBAT}}$ was monitored by inserting the thermocouple in the left side of IBAT.

These variables were recorded before an injection of orexin A (1.5 nmol) into the lateral cerebral ventricle and over a period of 2 hours after the injection. The icv injection of orexin A was preceded by ip administration of saline (1st group) or $50 \mathrm{mg}$ risperidone (2nd group). The icv injection of saline was preceded by ip administration of saline (3rd group) or $50 \mathrm{mg}$ risperidone (4th group).

The orexin A (or saline) was delivered into the left cerebral ventricle by gravity flow over $2 \mathrm{~min}$. The cannula for the injection was $0.4 \mathrm{~mm}$ longer than the guide cannula. The baseline values of $\mathrm{T}_{\mathrm{C}}$ from all animals used were maintained constant by a heating pad. The electrical energy supplying the pad was not altered during the experimental period.

\section{Histology}

At the end of the experiment, the location of the cannula was checked. A stain (bromophenol blue) was injected into the lateral ventricle, the volume of the stain being the same as the volume used for drug administration. The rats were then injected with an overdose of pentobarbital (150 mg/kg b.w.) and were perfused with $0.9 \% \mathrm{NaCl}$ followed by $10 \%$ formalin solution. The brain was removed and stored in the formalin solution. After a few days, $50 \mu \mathrm{m}$ coronal sections of the fixed brain were cut and stained with neutral red.

\section{Statistical analysis}

The values are presented as means \pm S.E.M. Statistical analysis was performed using analysis of variance. Multiple comparisons were performed by Newman-Keuls post hoc test.

\section{Results}

Figure 1 shows the percentage changes in the firing rate of the nerves to IBAT. The icv injection of orexin increased the firing rate in the rats with ip injection of saline and this rise was enhanced in the animals with ip injection of risperidone. The ip injection of risperidone or saline did not cause any modification in rats with icv injection of saline.

The analysis of variance showed significant effects for risperidone $[F(1,20)=8.9, p<0.01]$, for orexin $[F(1,20)$
$=42.8, \mathrm{p}<0.01]$, for time $[\mathrm{F}(4,80)=24.7, \mathrm{p}<0.01]$, for interaction risperidone $\mathrm{x}$ orexin $[\mathrm{F}(1,20)=6.9, \mathrm{p}<0.05]$, orexin $\mathrm{x}$ time $[\mathrm{F}(4,80)=24.6, \mathrm{p}<0.01]$.

The baseline absolute values $43.4 \pm 6.8$ spikes $/ 5 \mathrm{~s}$ in the 1st group, $44.2 \pm 7.7$ in the 2 nd group, $46.9 \pm 8.1$ in the 3 rd group and $47.7 \pm 8.6$ in the 4 th group. There were no differences in the baseline absolute values of all groups (for examples of the changes in firing rate see Figure 2).

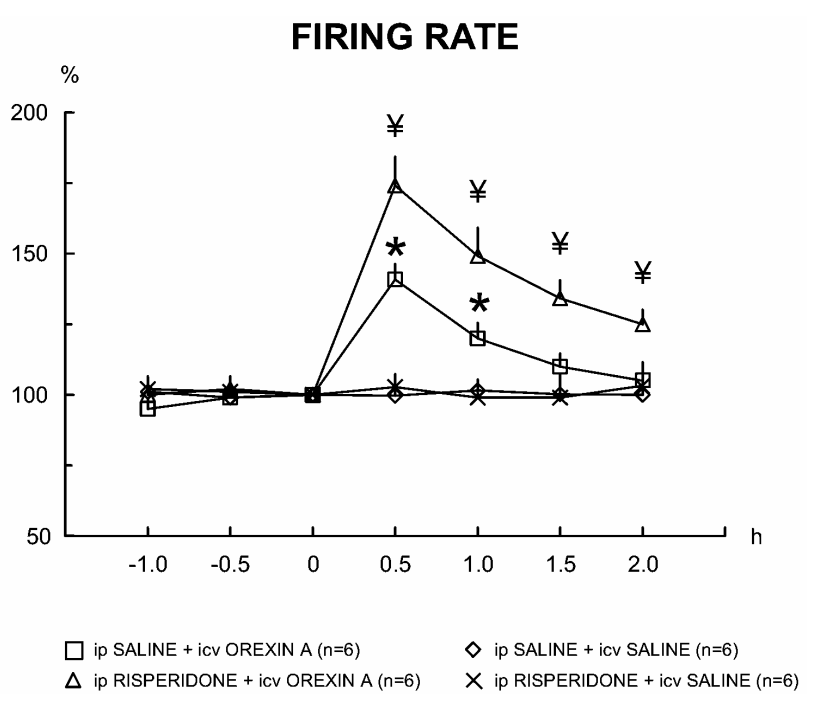

Fig. 1. Means \pm S.E.M. of percentage changes in firing rate of nerves to interscapular brown adipose tissue. Intraperitoneal (ip) injection of saline or risperidone $(50 \mathrm{mg} / \mathrm{kg} \mathrm{bw})$ was made at $-0.5 \mathrm{~h}$. Intracerebroventricular (icv) injection of saline or orexin $A$ $(1.5 \mathrm{nmol})$ was made at time 0 . ( $\mathbf{\Psi})$ : difference by post-hoc test $(p<0.05)$ between ip-saline + icv-orexin and ip-risperidone + icvsaline; $(*)$ : difference by post-hoc test $(p<0.05)$ between ip-saline + icv-orexin and ip-saline + icv-saline.

Figure 3 illustrates $\mathrm{T}_{\text {IBAT }}$ changes. The icv injection of orexin increased $\mathrm{T}_{\mathrm{IBAT}}$ in animals with ip injection with saline. Risperidone increased the effects of orexin. The ip injection of risperidone did not cause any modification in rats with icv injection of saline. The analysis of variance showed significant effects for risperidone $[\mathrm{F}(1,20)=65.0, \mathrm{p}<0.01]$, for orexin $[\mathrm{F}(1,20)=$ $143.8, \mathrm{p}<0.01]$, for time $[\mathrm{F}(4,80)=93.6, \mathrm{p}<0.01]$, for interaction risperidone $\mathrm{x}$ orexin $[\mathrm{F}(1,20)=66.9, \mathrm{p}<0.01]$, risperidone $\mathrm{x}$ time $[\mathrm{F}(4,80)=39.0, \mathrm{p}<0.01]$, orexin $\mathrm{x}$ time $[\mathrm{F}(4,80)=94.0, \mathrm{p}<0.01]$, risperidone $\mathrm{x}$ orexin $\mathrm{x}$ time $[\mathrm{F}(4,80)=39.3, \mathrm{p}<0.01]$.

Figure 4 illustrates $T_{C}$ changes. Orexin induced a rise in the rats with ip administration of saline. The injection of risperidone increased the hyperthermia due to orexin. Risperidone did not modify the temperature of rats with icv injection of saline. 


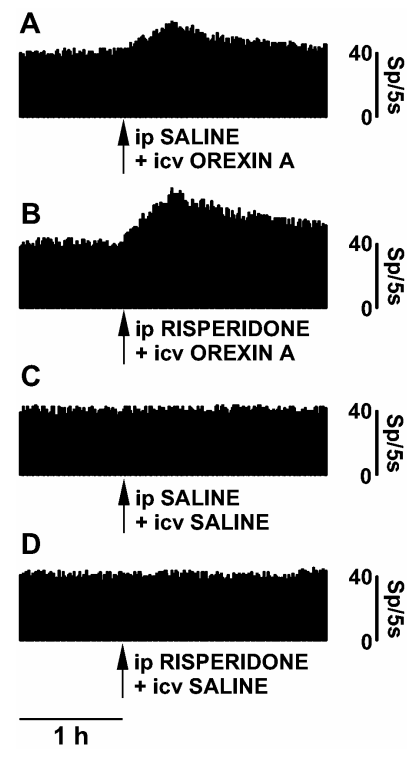

Fig. 2. Actual firing rate changes in a rat receiving intraperitoneal (ip) injection of saline plus intracerebroventricular (icv) injection of orexin A (panel $\mathbf{A}$ ) or saline (panel $\mathbf{C}$ ), and in a rat receiving ip injection of risperidone plus icv injection of orexin $\mathbf{A}$ (panel $\mathbf{B}$ ) or saline (panel D). The arrow indicates the time of icv injection. Ip administration was made $0.5 \mathrm{~h}$ before the icv injection.

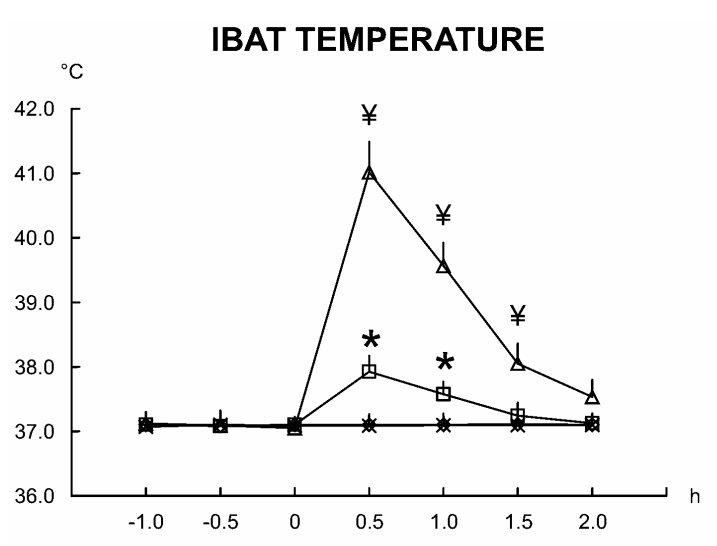

$$
\begin{array}{ll}
\square \text { ip SALINE + icv OREXIN A }(n=6) & \diamond \text { ip SALINE + icv SALINE }(n=6) \\
\Delta \text { ip RISPERIDONE + icv OREXIN A }(n=6) & \times \text { ip RISPERIDONE + icv SALINE }(n=6)
\end{array}
$$

Fig. 3. Means \pm S.E.M. of values of temperature in the interscapular brown adipose tissue (IBAT). Intraperitoneal (ip) injection of saline or risperidone $(50 \mathrm{mg} / \mathrm{kg} \mathrm{bw})$ was made at $-0.5 \mathrm{~h}$. Intracerebroventricular (icv) injection of saline or orexin $A$ $(1.5 \mathrm{nmol})$ was made at time 0 . ( $\mathbf{\Psi})$ : difference by post-hoc test $(p<0.05)$ between ip-saline + icv-orexin and ip-risperidone + icvsaline; $(*)$ : difference by post-hoc test $(p<0.05)$ between ip-saline + icv-orexin and ip-saline + icv-saline.

The analysis of variance showed significant effects for risperidone $[\mathrm{F}(1,20)=62.3, \mathrm{p}<0.01]$, for orexin $[\mathrm{F}(1,20)=169.7, \mathrm{p}<0.01]$, for time $[\mathrm{F}(4,80)=106.1$, $\mathrm{p}<0.01]$, for interaction risperidone $\mathrm{x}$ orexin $[\mathrm{F}(1,20)=$ 64.1, $\mathrm{p}<0.01]$, risperidone $\mathrm{x}$ time $[\mathrm{F}(4,80)=55.9, \mathrm{p}<0.01]$, orexin $\mathrm{x}$ time $[\mathrm{F}(4,80)=105.9, \mathrm{p}<0.01]$, risperidone $\mathrm{x}$ orexin $\mathrm{x}$ time $[\mathrm{F}(4,80)=56.7, \mathrm{p}<0.01]$.
Figure 5 shows modifications of the heart rate. The icv injection of orexin increased the heart rate in the rats with ip injection of saline and this rise was enhanced in the animals with ip injection of risperidone. The ip injection of risperidone or saline did not cause any modification in rats with icv injection of saline.

The analysis of variance showed significant effects for orexin $[F(1,20)=39.2, p<0.01]$, for time $[F(4,80)=$ 95.7, $\mathrm{p}<0.01]$, for interaction risperidone $\mathrm{x}$ time $[\mathrm{F}(4,80)=$ 5.1, $\mathrm{p}<0.05]$, orexin $\mathrm{x}$ time $[\mathrm{F}(4,80)=95.8, \mathrm{p}<0.01]$, risperidone $\mathrm{x}$ orexin $\mathrm{x}$ time $[\mathrm{F}(4,80)=5.4, \mathrm{p}<0.05]$.

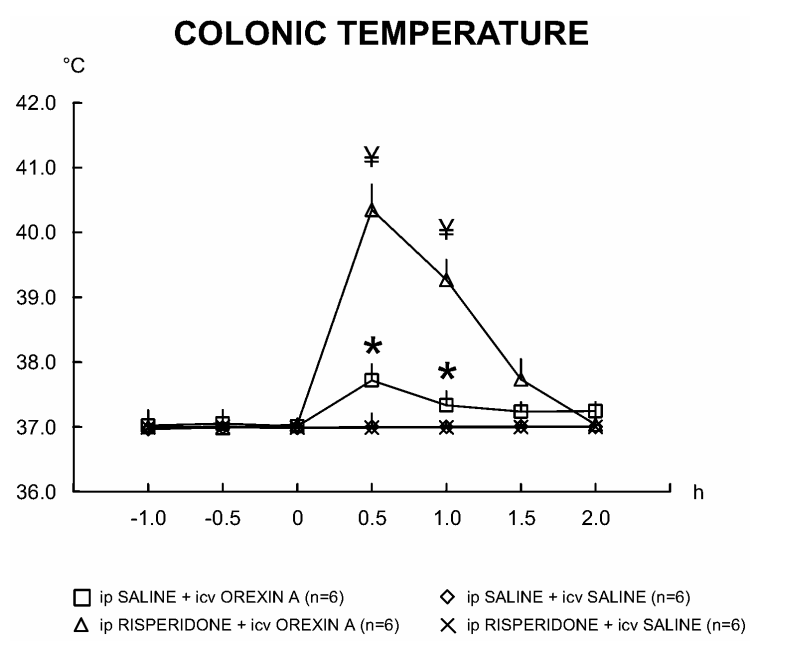

Fig. 4. Means \pm S.E.M. of values of colonic temperature. Intraperitoneal (ip) injection of saline or risperidone ( $50 \mathrm{mg} / \mathrm{kg} \mathrm{bw})$ was made at $-0.5 \mathrm{~h}$. Intracerebroventricular (icv) injection of saline or orexin $A(1.5 \mathrm{nmol})$ was made at time 0 . (¥): difference by posthoc test $(p<0.05)$ between ip-saline + icv-orexin and ip-risperidone + icv-saline; $(*)$ : difference by post-hoc test $(p<0.05)$ between ipsaline + icv-orexin and ip-saline + icv-saline.

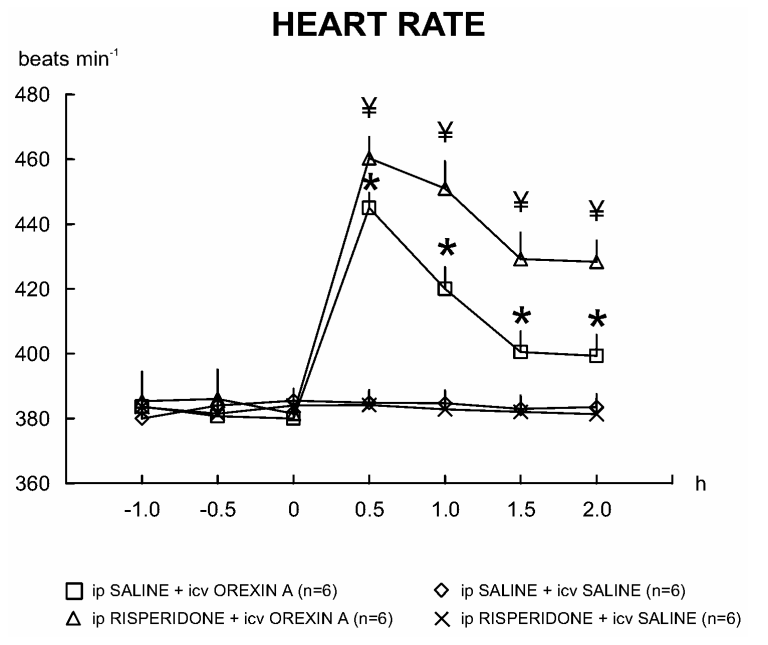

Fig. 5. Means \pm S.E.M. of values of heart rate. Intraperitoneal (ip) injection of saline or risperidone $(50 \mathrm{mg} / \mathrm{kg} \mathrm{bw})$ was made at $-0.5 \mathrm{~h}$. Intracerebroventricular (icv) injection of saline or orexin $A$ $(1.5 \mathrm{nmol})$ was made at time 0 . ( $\mathbf{\Psi})$ : difference by post-hoc test $(p<0.05)$ between ip-saline + icv-orexin and ip-risperidone + icvsaline; $(*)$ : difference by post-hoc test $(p<0.05)$ between ip-saline + icv-orexin and ip-saline + icv-saline. 


\section{Discussion}

The findings of this experiment are the first to demonstrate that risperidone potentiates the sympathetic and hyperthermic reactions induced by an icv injection of orexin A. The influence of risperidone on the effects due to orexin A is different from the influence exerted by other antipsychotic drugs, such as haloperidol and clozapine. Indeed, these last two drugs induce a decrease of hyperthermia in rat with an icv injection of orexin A (Monda et al. 2003b, 2004b).

Risperidone is an atypical antipsychotic drug that possesses 5-hydroxytryptamine $5-\mathrm{HT}_{2}$ receptor antagonism combined with milder dopamine $\mathrm{D}_{2}$ receptor antagonism (Grant and Fitton 1994, Ota et al. 2002). A risperidone injection potentiates hyperthermic effects of orexin A, indicating that these thermic reactions involve serotoninergic and dopaminergic systems.

This experiment indicates that a $5-\mathrm{HT}_{2}$ receptor antagonism is stronger than a dopamine $\mathrm{D}_{2}$ receptor antagonism in the induction of the amplified hyperthermia due to orexin A.

The results of this experiment suggest that the mechanism inducing hypothermia, as occasional side effect of psychiatric therapy with risperidone, is independent of the involvement of orexinergic system. On the other hand, rare cases of high fever have been described in the patients treated with risperidone. Thus, the findings of the present experiment can suggest an involvement of orexinergic system in the fever due to risperidone.

Although the precise mechanisms of the effect of risperidone must be examined by using more specific antagonists for serotonin and dopamine receptors, the results of our experiment clearly indicate that the sympathetic and thermogenic effects of orexin A are strongly increased by risperidone. These data are useful for addressing the choice of antipsychotic drugs for the therapy of mental disorders. Furthermore, the treatment of rare but perilous hypothermia induced by risperidone could include substances, which utilize the orexinergic pathway to elevate body temperature. This pathway is not blocked by risperidone, as demonstrated by our experiments.

The acute dose of risperidone $(50 \mathrm{mg} / \mathrm{kg}$ b.w.) is not much higher than the doses utilized by other authors (Marchese et al. 2004). Furthermore, risperidone alone does not induce temperature changes, indicating that this dose has no toxic effect in rats without injection of orexin A.

The icv injection of orexin $\mathrm{A}$ increases the temperature of IBAT, which is the most important effector of non- shivering thermogenesis in the rat (Cannon et al. 1998), illustrating that the rise in heat production is also due to the activation of thermogenesis unrelated to muscle activity. The increase in colonic temperature emphasizes the effect of orexin A on "core" temperature suggesting the inclusion of orexin A among the peptides controlling body temperature.

The present experiment confirms the strong influence of orexin A on body temperature, independently of eating behavior. The name assigned to orexin A, called primarily hypocretin A (De Lecea et al. 1998), was due to the strong increase in food intake after administration of this peptide, assigning a fundamental role in the induction of food intake (Wolf 1998). Since risperidone potentiates hyperthermic effects of orexin A, the present findings confirm that orexin A induces strong elevations of body temperature in anesthetized rats, thus independently on food intake. For this reason, we can insist to suggest the term "hyperthermine A" as an additional denomination of "orexin A" (Monda et al. 2003a, 2004a).

The rise of the sympathetic discharge induced by orexin A is corroborated by an increase in heart rate, although a possible reduction on vagal tone cannot be excluded. Since a possible modification of the vagal tone cannot be demonstrated by a registration of sympathetic nerves to IBAT, the vagal tone reduction could explain the sustained increase in heart rate, which is longer than the increase in firing rate of nerves to IBAT. Since van den Pol (1999) demonstrated a direct innervation of the intermediolateral column of spinal cord by orexin-fibers, there might be yet another direct pathway of the orexininduced activation of the sympathetic nervous system.

\section{Acknowledgements}

This study has been supported by a grant of Regione Campania.

\section{References}

ANANTH J, PARAMESWARAN S, GUNATILAKE S, BURGOYNE K, SIDHOM T: Neuroleptic malignant syndrome and atypical antipsychotic drugs. J Clin Psychiatry 65: 464-470, 2004. 
CANNON BJ, HOUŠTĚK J, NEDERGAARD J: Brown adipose tissue. More than an effector of thermogenesis. Ann NY Acad Sci 856: 171-187, 1998.

DE LECEA L, KILDUFF TS, PEYRON C, GAO XB, FOYE PE, DANIELSON PE, FUKUHARA C, BATTENBERG ELF, GAUTVIK VT, BARTLETT II FS, FRANKEL WN, VAN DEN POL AN, BLOOM FE, GAUTVIK KM AND SUTCLIFFE JG: The hypocretins: two hypothalamic peptides with neuroexcitatory activity. Proc Natl Acad Sci USA 95: 322-327, 1998.

GRANT S, FITTON A: Risperidone. A review of its pharmacology and therapeutic potential in the treatment of schizophrenia. Drugs 48: 253-273, 1994.

HALLORAN LL, BERNARD DW: Management of drug-induced hyperthermia. Curr Opin Pediatr 16: 211-215, 2004.

LUBKIN A, STRICKER-KRONGRAD A: Independent feeding and metabolic action of orexins in mice. Biochem Biophys Res Commun 253: 241-245, 1998.

MASAN PS: Atypical antipsychotics in the treatment of affective symptoms: a review. Ann Clin Psychiatry 16: 3-13, 2004.

MARCHESE G, BARTHOLINI F, CASU MA, RUIU S, CASTI P, CONGEDDU E, TAMBARO S, PANI L: Haloperidol versus risperidone on rat "early onset" vacuous chewing. Behav Brain Res 149: 9-16, 2004.

MONDA M, VIGGIANO A, MONDOLA P, DE LUCA V: Inhibition of prostaglandin synthesis reduces hyperthermic reactions induced by hypocretin-1/orexin A. Brain Res 909: 68-74, 2001.

MONDA M, VIGGIANO A, DE LUCA V: A paradoxical effect of orexin A: the hypophagia induced by hyperthermia. Brain Res 961: 220-228, 2003a.

MONDA M, VIGGIANO A, DE LUCA V: Haloperidol reduces the sympathetic and thermogenic activation induced by orexin A. Neurosci Res 45: 17-23, 2003 b.

MONDA M, VIGGIANO AN, VIGGIANO AL, FUCCIO F, DE LUCA V: Cortical spreading depression blocks the hyperthermic reaction induced by orexin A. Neuroscience 123: 567-574, 2004a.

MONDA M, VIGGIANO AN, VIGGIANO AL, FUCCIO F, DE LUCA V: Clozapine blocks the hyperthermia induced by orexin A in the rat. Physiol Res 53: 507-513, 2004b.

OTA M, MORI K, NAKASHIMA A, KANEKO YS, FUJIWARA K, ITOH M, NAGASAKA A, OTA A: Peripheral injection of risperidone, an atypical antipsychotic, alters the body weight gain of rats. Clin Exp Pharmacol Physiol 29: 980-989, 2002.

PELleGRINO LJ, PELleGRINO AS, CUSHMAN AJ: A Stereotaxic Atlas of the Rat Brain. Plenum Press, New York, 1979.

RAZAQ M, SAMMA M: A case of risperidone-induced hypothermia. Am J Ther 11: 229-230, 2004.

SWEET DC, LEVINE AS, BILLINGTON CJ, KOTZ CM: Feeding response to central orexins. Brain Res 821: 535$538,1999$.

VAN DEN POL AN: Hypothalamic hypocretin (orexin): robust innervation of the spinal cord. J Neurosci 19: 3171-3182, 1999.

WOLF G: Orexins: a newly discovered family of hypothalamic regulators of food intake. Nutr Rev 56: 172-173, 1998.

\section{Reprint requests}

Marcellino Monda, Dipartimento di Medicina Sperimentale, Sezione di Fisiologia Umana, Seconda Università di Napoli, Via Costantinopoli 16, 80138 Napoli, Italy. E-mail: marcellino.monda@unina2.it 